\title{
Oxidation kinetics and inverse isotope effect of marine nitrite-oxidizing isolates
}

\author{
Juliane Jacob ${ }^{1,2, *}$, Boris Nowka ${ }^{3}$, Véronique Merten ${ }^{4}$, Tina Sanders ${ }^{1}$, Eva Spieck ${ }^{3}$, \\ Kirstin Dähnke ${ }^{1}$
}

\author{
${ }^{1}$ Helmholtz Center Geesthacht, Institute of Coastal Research, Max-Planck-Str. 1, 21502 Geesthacht, Germany \\ ${ }^{2}$ Institute of Biogeochemistry and Marine Chemistry, University of Hamburg, Bundesstr. 55, 20146 Hamburg, Germany \\ ${ }^{3}$ Biozentrum Klein Flottbek, Department of Microbiology and Biotechnology, University of Hamburg, Ohnhorststr. 18, \\ 22609 Hamburg, Germany
}

${ }^{4}$ GEOMAR Helmholtz Center for Ocean Research Kiel, Wischhofstr. 1-3, 24148 Kiel, Germany

\begin{abstract}
Nitrification, the step-wise oxidation of ammonium to nitrite and nitrate, is important in the marine environment because it produces nitrate, the most abundant marine dissolved inorganic nitrogen (DIN) component and N-source for phytoplankton and microbes. This study focused on the second step of nitrification, which is carried out by a distinct group of organisms, nitrite-oxidizing bacteria (NOB). The growth of NOB is characterized by nitrite oxidation kinetics, which we investigated for 4 pure cultures of marine NOB (Nitrospina watsonii 347, Nitrospira sp. Ecomares 2.1, Nitrococcus mobilis 231, and Nitrobacter sp. 311). We further compared the kinetics to those of non-marine species because substrate concentrations in marine environments are comparatively low, which likely influences kinetics and highlights the importance of this study. We also determined the isotope effect during nitrite oxidation of a pure culture of Nitrospina (Nitrospina watsonii 347) belonging to one of the most abundant marine NOB genera, and for a Nitrospira strain (Nitrospira sp. Ecomares 2.1). The enzyme kinetics of nitrite oxidation, described by Michaelis-Menten kinetics, of 4 marine genera are rather narrow and fall in the low end of halfsaturation constant $\left(K_{\mathrm{m}}\right)$ values reported so far, which span over 3 orders of magnitude between 9 and $>1000 \mu \mathrm{M} \mathrm{NO}_{2}{ }^{-}$. Nitrospina has the lowest $K_{\mathrm{m}}\left(19 \mu \mathrm{M} \mathrm{NO}_{2}{ }^{-}\right)$, followed by Nitrobacter $(28 \mu \mathrm{M}$ $\left.\mathrm{NO}_{2}^{-}\right)$, Nitrospira $\left(54 \mu \mathrm{M} \mathrm{NO}_{2}{ }^{-}\right)$, and Nitrococcus $\left(120 \mu \mathrm{M} \mathrm{NO}_{2}{ }^{-}\right)$. The isotope effects during nitrite oxidation by Nitrospina watsonii 347 and Nitrospira sp. Ecomares 2.1 were $9.7 \pm 0.8$ and $10.2 \pm$ $0.9 \%$, respectively. This confirms the inverse isotope effect of NOB described in other studies; however, it is at the lower end of reported isotope effects. We speculate that differences in isotope effects reflect distinct nitrite oxidoreductase (NXR) enzyme orientations.
\end{abstract}

KEY WORDS: Nitrification $\cdot$ Nitrite-oxidizing bacteria $\cdot$ Isotope effect $\cdot$ Enzyme kinetics $\cdot$ Marine environment

\section{INTRODUCTION}

In the global ocean, nitrate is the dominant dissolved inorganic nitrogen (DIN) component. Nitrate sinks include assimilation (mainly but not exclusively by phytoplankton) and respiratory processes, like dissimilatory nitrate reduction to ammonium (DNRA) and denitrification (e.g. Kraft et al. 2014). Only $\mathrm{N}_{2}$

${ }^{*}$ Corresponding author: juliane.jacob@uni-hamburg.de production (via denitrification or anammox) permanently removes nitrogen from the system. Nitrate is synthesized via nitrification, the step-wise oxidation of ammonia to nitrite and nitrate. This study focuses on the second step, which is carried out by chemolithoautotrophic nitrite-oxidizing bacteria (NOB). Marine nitrite concentrations are generally low; however, there are regions where nitrite does accumulate

(C) The authors 2017. Open Access under Creative Commons by Attribution Licence. Use, distribution and reproduction are unrestricted. Authors and original publication must be credited. 
to micromolar concentrations. On the one hand, this occurs in the 'primary nitrite maximum' (PNM) at the base of the euphotic zone due to decoupling of ammonia and nitrite oxidation or phytoplankton release of nitrite (Olson 1981, Dore \& Karl 1996, Lomas \& Lipschultz 2006). On the other hand, nitrite also occurs in the 'secondary nitrite maximum' (SNM), which is found in oxygen-depleted deeper water bodies, where nitrite probably stems from nitrate reduction to nitrite and ammonia oxidation (Lam et al. 2011).

Important oxygen minimum zones (OMZs) with significant nitrite accumulation are located in the Arabian Sea, the eastern tropical North Pacific, and the eastern tropical South Pacific (cf. overview in Wright et al. 2012). Even though OMZs make up $<0.1 \%$ of the total ocean volume (Codispoti et al. 2001), they are responsible for 30 to $50 \%$ of the global marine nitrogen loss (Gruber \& Sarmiento 1997), because high rates of nitrification and DNRA fuel nitrogen release via anammox and/or denitrification (e.g. Lam \& Kuypers 2011, Kalvelage et al. 2013). Although nitrification is an aerobic process, it is also a key process in OMZs, as some nitrifiers are also active under oxygen depleted conditions (Bristow et al. 2016).

In this manuscript, we focused on marine NOB pure cultures, which gain energy from the chemical conversion of nitrite to nitrate and use $\mathrm{CO}_{2}$ as a carbon source (Watson et al. 1989, Fiencke et al. 2005):

$$
\begin{gathered}
\mathrm{NO}_{2}{ }^{-}+\mathrm{H}_{2} \mathrm{O} \rightarrow \mathrm{NO}_{3}^{-}+2 \mathrm{H}^{+}+2 \mathrm{e}^{-} \\
2 \mathrm{H}^{+}+2 \mathrm{e}^{-}+1 / 2 \mathrm{O}_{2} \rightarrow \mathrm{H}_{2} \mathrm{O} \\
\mathrm{NO}_{2}^{-}+1 / 2 \mathrm{O}_{2} \rightarrow \mathrm{NO}_{3}^{-}
\end{gathered}
$$

Four NOB phyla are known: Nitrospirae, Nitrospinae, Proteobacteria, and Chloroflexi. The genus Nitrospira (Watson et al. 1986) belongs to the phylum Nitrospirae (Ehrich et al. 1995), Nitrospina (Watson \& Waterbury 1971) is phylogenetically affiliated with Nitrospinae (Lücker et al. 2013, Spieck et al. 2014), just like the Candidatus Nitromaritima (recently identified based on metagenomic data; Ngugi et al. 2016). Nitrobacter (Winogradsky 1892, Woese et al. 1984), Nitrococcus (Watson \& Waterbury 1971, Woese et al. 1985), and Nitrotoga (Alawi et al. 2007) belong to the Alpha-, Gamma- or Betaproteobacteria, and Nitrolancea (Sorokin et al. 2012) is a member of the phylum Chloroflexi.

NOB are phylogenetically heterogeneous (Teske et al. 1994), and cover a wide range of preferences regarding environmental conditions such as temperature or substrate concentration (De Boer et al. 1991). In the marine realm, Nitrobacter, Nitrococcus, Nitro- spina, Nitrospira, and Candidatus Nitromaritima have been found. Additionally, Nitrotoga has been detected in a marine recirculation aquaculture system (Keuter et al. 2017). However, few strains were isolated, and there is limited knowledge on their overall distribution and abundance (Watson \& Waterbury 1971, Watson et al. 1986, Ward 2011, Ngugi et al. 2016). Established data for marine NOB are scarce and mainly available for Nitrobacter (Ward \& Carlucci 1985), including Nitrobacter sp. 355 (Buchwald \& Casciotti 2010) isolated from Black Sea surface water, and for Nitrospira marina from the Gulf of Maine (Watson et al. 1986).

Nitrite oxidation is catalysed by nitrite oxidoreductase (NXR) enzymes, which shuttle 2 electrons per reaction into the respiratory chain. NXR belongs to a type II DMSO reductase-like family of molybdopterin-binding enzymes (Lücker et al. 2010, Lücker et al. 2013). NXR in different genera of NOB varies in its molecular mass, orientation, and classes of cytochromes that are used in the electron transport chain. NXR is a membrane-bound enzyme associated with the cytoplasmic membrane, and consists of 3 subunits: the catalytical NxrA, the electron-chanelling NxrB, and a putative NxrC as membrane anchor (Sundermeyer-Klinger et al. 1984, Lücker et al. 2010). The substrate-binding NxrA subunit faces the periplasmic space in Nitrospina (Spieck \& Bock 2005, Lücker et al. 2013) and Nitrospira (Spieck et al. 1998, Lücker et al. 2010), but is oriented towards the cytoplasm in Nitrobacter, Nitrococcus, and Nitrolancea (Spieck et al. 1996, Sorokin et al. 2012).

The activity of NXR can be described based on Michaelis-Menten kinetics, i.e. the half-saturation constant $\left(K_{\mathrm{m}}\right)$ and the maximum nitrite oxidation activity $\left(V_{\max }\right)$. Based on these parameters and the idea of $K$ - and $r$-selection (MacArthur \& Wilson 1967 , Andrews \& Harris 1986), Schramm et al. (1999) classified Nitrospira as a $K$-strategist and Nitrobacter as a $r$-strategist. $K$-strategy originally meant selection for competitive ability in crowded populations, and $r$ strategy referred to selection for high population growth in uncrowded populations (MacArthur \& Wilson 1967). $K$-strategists among microbes have high substrate affinities at low substrate concentrations, and $r$-strategists have high maximum specific growth and substrate utilization rates at high substrate concentrations (Andrews \& Harris 1986). So far, the kinetics of nitrite oxidation have not been investigated for marine NOB pure cultures. Recent investigations of natural assemblages in OMZs focused on $\mathrm{O}_{2}$ dependence during nitrite oxidation and found a very high $\mathrm{O}_{2}$ affinity, which supports the relevance of 
nitrification even in the core of OMZs (Bristow et al. 2016, Peng et al. 2016).

Another technique is based on natural abundances of stable nitrite isotopes to shed light on the origin and fate of nitrite, which have been applied, for example, in the PNM in the central California Current and in a European river (Santoro et al. 2013, Jacob et al. 2016). Nitrite oxidation is coupled to a rare inverse isotope effect, so that the nitrite pool is subsequently depleted in ${ }^{15} \mathrm{~N}$ during nitrite oxidation (Casciotti 2009). However, this isotope effect has only been investigated in Nitrococcus mobilis 231, Nitrobacter sp. 355, and Nitrospira marina. It is known that the isotope effect of a specific reaction can vary depending on enzyme properties and genetic diversity (Casciotti et al. 2003), but so far, the database has been too sparse to assess the variability of the isotope effect of nitrite oxidation and its link to enzyme variability and Michaelis-Menten kinetics.

In this study, we investigated 4 marine species (Nitrospira sp. Ecomares 2.1, Nitrospina watsonii 347, Nitrobacter sp. 311, and Nitrococcus mobilis 231) for their nitrite oxidation kinetics and 2 species (Nitrospira sp. Ecomares 2.1, Nitrospina watsonii 347) for their specific kinetic isotope effects, and compared those to non-marine species. We hypothesized that the environmental conditions in the marine realm (e.g. low substrate concentration in comparison to terrestrial habitats) should be reflected in enzyme kinetics, and aimed to investigate a potential link between enzyme kinetics and the isotope effects of nitrite oxidation.

\section{MATERIALS AND METHODS}

\section{Bacterial strains and cultivation}

Nitrospira sp. Ecomares 2.1 was isolated from a moving-bed filter of an aquaculture system in Büsum, Germany, and has optimal growth conditions in 28 to $30^{\circ} \mathrm{C}$ seawater $(70 \%)$ (Keuter 2011). To date, Nitrospina has been found exclusively in marine habitats, and Nitrospina watsonii 347 was originally sampled from $100 \mathrm{~m}$ depth in the Black Sea (Spieck et al. 2014). Its temperature optimum is $28^{\circ} \mathrm{C}$ in $70 \%$ seawater (Watson \& Waterbury 1971). Nitrospira and Nitrospina have substrate optima from 0.5 to $3 \mathrm{mM}$ (Keuter et al. 2011, Spieck et al. 2014). Nitrobacter sp. 311 was isolated from surface waters of the tropical Eastern Atlantic Ocean near the west coast of central Africa (J. Waterbury pers. comm. in Starkenburg et al. 2008). Nitrococcus mobilis 231 was iso- lated from surface waters of the South Pacific Ocean near the Galapagos Archipelago. So far, it is the only isolate of this genus, and has to date been found exclusively in marine habitats. Optimal growth conditions are 25 to $30^{\circ} \mathrm{C}$ in 70 to $100 \%$ seawater (Watson \& Waterbury 1971).

\section{Chemical analyses}

For nitrite oxidation kinetics experiments, nitrite and nitrate concentrations of Nitrospira, Nitrospina, Nitrobacter, and Nitrococcus cultures were analysed by high-performance liquid chromatography (HPLC) coupled to an ion pair chromatograph (LiChrospher RP-18 column; Merck) (Meincke et al. 1992), and UV detection in an automated system (LaChrom Elite HPLC system; VWR). Cell protein concentration was determined based on the bicinchoninic acid method (Smith et al. 1985) after cell lysis in $0.15 \mathrm{M} \mathrm{NaOH}$ and incubation at $90^{\circ} \mathrm{C}$ for $30 \mathrm{~min}$.

For nitrite isotope fractionation experiments, nitrite concentrations of Nitrospina watsonii 347 incubations were analysed photometrically using standard colorimetric techniques (Grasshoff et al. 2009). Nitrite and nitrate concentrations of Nitrospira sp. Ecomares 2.1 incubations were measured with an HPLC system (Jasco) (Meincke et al. 1992). Both methods were in good agreement.

\section{Activity measurements and calculation of nitrite oxidation kinetics}

Nitrite oxidation kinetics were calculated based on activity measurements performed after Nowka et al. (2015). Nitrospira sp. Ecomares 2.1, Nitrospina watsonii 347, Nitrobacter sp. 311, and Nitrococcus mobilis 231 were grown in biological replicates (see Table 2) in $1 \mathrm{l}$ flasks, each with $500 \mathrm{ml}$ marine NOBmedium at $28^{\circ} \mathrm{C}$ (modified Spieck \& Lipski 2011, after Watson \& Waterbury 1971). Nitrite-oxidation dependent oxygen consumption was analysed in a microrespiration system (Unisense AS), which was constructed with a 1 channel oxygen sensor amplifier (OXY-Meter), a Clark-type oxygen microsensor (OX$\mathrm{MR}$, polarized for at least $48 \mathrm{~h}$ before use), a stirring system with glass-coated magnets, $2 \mathrm{ml}$ glass chambers with glass stoppers, a rack for 8 chambers, and the data acquisition software MicOx 3.0. All incubations were stirred at $200 \mathrm{rpm}$ in a recirculated water bath in thermostat-regulated rooms. Twelve to $48 \mathrm{~h}$ after complete nitrite consumption (early stationary 
phase), sub-samples were transferred to $2 \mathrm{ml}$ glass chambers, which were sealed with glass stoppers. The measurements started with nitrite concentrations of up to $150 \mu \mathrm{M}$ for Nitrospira sp. Ecomares 2.1, $230 \mu \mathrm{M}$ for Nitrospina watsonii 347, $472 \mu \mathrm{M}$ for Nitrobacter sp. 311, and $1250 \mu \mathrm{M}$ for Nitrococcus mobilis 231 (cf. Nowka et al. 2015) (see Fig. 1).

Oxygen consumption rate profiles based on a minimum of 5 different concentrations and at least triplicate incubations of each NOB strain were used to calculate specific oxidation kinetics. Nitrite consumption was calculated from oxygen consumption based on a ratio of $2: 1$. These consumption data were used to calculate oxidation kinetics based on Michaelis-Menten kinetics:

$$
V=\left(\frac{V_{\max } \times[S]}{K_{\mathrm{m}}+[S]}\right)
$$

where $V$ is the activity, $V_{\max }$ is the maximum specific activity ( $\mu \mathrm{mol} \mathrm{mg}$ protein ${ }^{-1} \mathrm{~h}^{-1}$ ), $K_{\mathrm{m}}$ is the half-saturation constant for nitrite oxidation $(\mu \mathrm{M})$, and $[S]$ is the nitrite concentration in $\mu \mathrm{M}$. Note that we did not work with purified enzyme, but as growth can be discounted due to the short-term incubations of only a few hours, the use of the terms $K_{\mathrm{m}}$ and $V_{\max }$ is justified.

\section{Setup for nitrite fractionation experiments}

The batch experiments of Nitrospina watsonii 347 and Nitrospira sp. Ecomares 2.1 represent closed systems during a relatively short time, where any nitrite loss is due to nitrite oxidation. Sterile control flasks were incubated in duplicate to exclude abiotic nitrite turnover.

Both NOB strains were cultured in batch incubations of marine NOB-medium with varying amounts of nitrite (modified Spieck \& Lipski 2011, after Watson \& Waterbury 1971) in the dark at $28^{\circ} \mathrm{C}$ without stirring. Flasks $(250 \mathrm{ml})$ with $100 \mathrm{ml}$ fresh growth medium were inoculated with $10 \mathrm{ml}$ active stock culture. The medium was then amended with nitrite of a known isotope value $\left(\delta^{15} \mathrm{~N}=-27.5 \%\right)$.

We performed 6 Nitrospira sp. Ecomares 2.1 and 7 Nitrospina watsonii 347 experiments, which had nitrite concentration between $\sim 100$ and $\sim 1600 \mu \mathrm{M}$ (Table 1), i.e. within the substrate optima for the respective species (Keuter et al. 2011, Spieck et al. 2014). Samples were taken daily until nitrite was consumed. At each sampling time, $6 \mathrm{ml}$ of culture were removed with a sterile pipette and centrifuged $(20 \mathrm{~min}$ at $16000 \times g)$. The supernatant was analysed for nutrient and isotope composition. Isotope effects of Nitrospira sp. Ecomares 2.1 and Nitrospina watsonii 347 were based on 3 to 11 technical replicates per nitrite concentration that showed a linear decrease in substrate concentration over time (Table 1).

\section{Isotope analyses}

Nitrite isotopes were analysed using the denitrifier method (Sigman et al. 2001, Casciotti et al. 2002, Böhlke et al. 2007). In brief, media samples were injected into a Stenotrophomonas nitrireducens bacteria suspension. These bacteria selectively reduce nitrite to $\mathrm{N}_{2} \mathrm{O}$ gas, which was then analysed on a Gas Bench II coupled to a Delta V isotope ratio mass spectrometer (Thermo Fisher Scientific). The sample volume was always adjusted to a final $\mathrm{N}_{2} \mathrm{O}$ gas amount of $5 \mathrm{nmol}$.

Isotope values are reported using the delta notation:

$$
\delta^{15} \mathrm{~N}[\% \text { vs. std }]=\left(\frac{\left(\frac{{ }^{15} \mathrm{~N}}{{ }^{14} \mathrm{~N}}\right)_{\text {sample }}}{\left(\frac{{ }^{15} \mathrm{~N}}{{ }^{14} \mathrm{~N}}\right)_{\text {std }}}-1\right) \times 1000
$$

where the standard for nitrogen is atmospheric $\mathrm{N}_{2}$.

All samples were analysed in replicate and against in-house potassium nitrite and sodium nitrite standards with known $\delta^{15} \mathrm{~N}$ values of -81.5 and $-27.5 \%$, determined independently via elementaranalysator- 
isotope ratio mass spectrometry analysis. The standard deviation of standards and replicates was $<0.3 \%$ o $(\mathrm{n}>3)$.

\section{Calculation of isotope effects}

The kinetic isotope effect, $\varepsilon$, can be calculated based on the Rayleigh closed-system equation (Mariotti et al. 1981, see Eq. 4), with samples of exponential growth phase only. Recently, some inconsistency has emerged in reporting isotope effects, with some authors reporting inverse fractionation with a negative sign. However, we refer to Mariotti et al. (1981) as one of the fundamental works on isotope effects, and decided to use their original notation. Hence, positive isotope effects indicate inverse fractionation:

$$
\varepsilon=\frac{\delta^{15} \mathrm{~N}_{\text {substrate }}-\delta^{15} \mathrm{~N}_{\text {initial }}}{\ln (f)}
$$

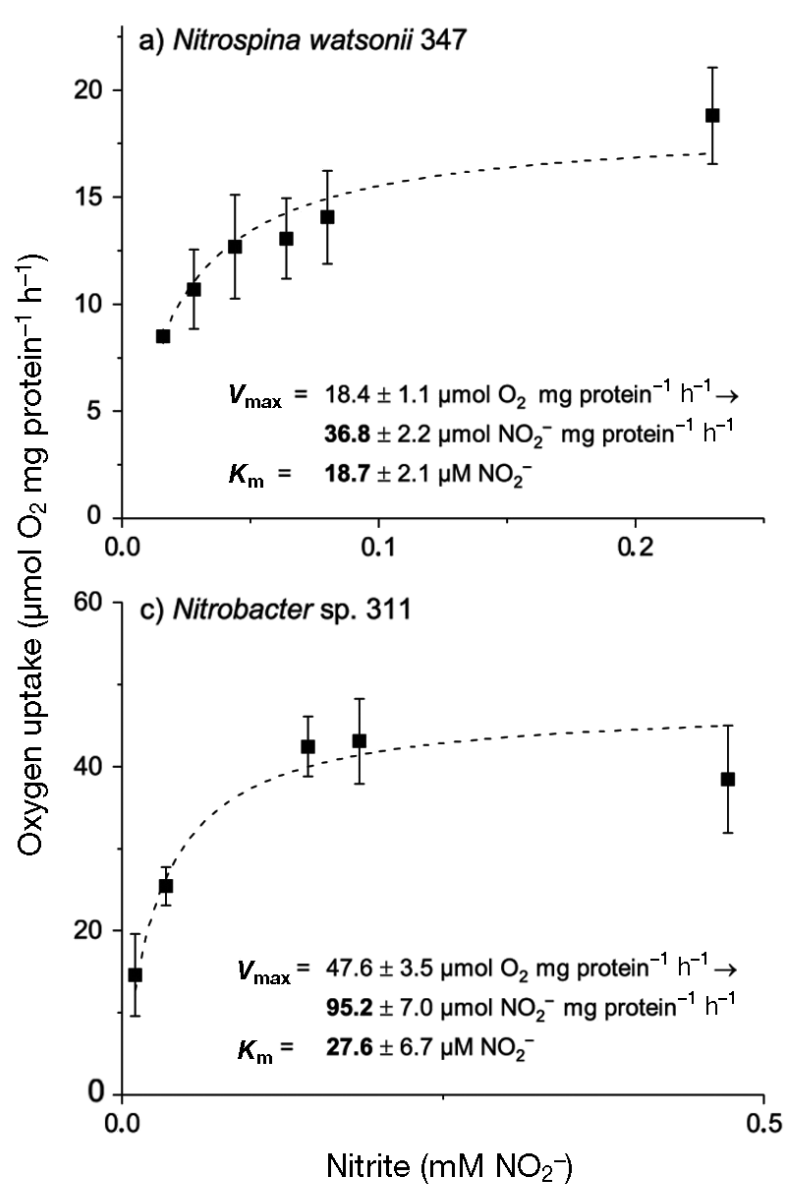

where $f$ is the remaining fraction of substrate at the time of sampling, and $\delta^{15} \mathrm{~N}_{\text {initial }}$ and $\delta^{15} \mathrm{~N}_{\text {substrate }}$ represent the initial isotope value of nitrite and the isotope value at the time of sampling, respectively.

\section{RESULTS}

\section{Nitrite oxidation kinetics}

The key parameters of nitrite oxidation kinetics are $V_{\max }$ and $K_{\mathrm{m}}$. They were assessed based on nitritedependent oxygen consumption. In nitrite-depleted, early-stationary-phase cultures, oxygen consumption was initially small, and increased within a few minutes after substrate addition. The $\mathrm{O}_{2}$ consumption rates depended on the added nitrite concentration and followed Michaelis-Menten kinetics (Fig. 1, Table 2). The $V_{\max }$ values of the investigated species revealed a clear differentiation of specific activities:
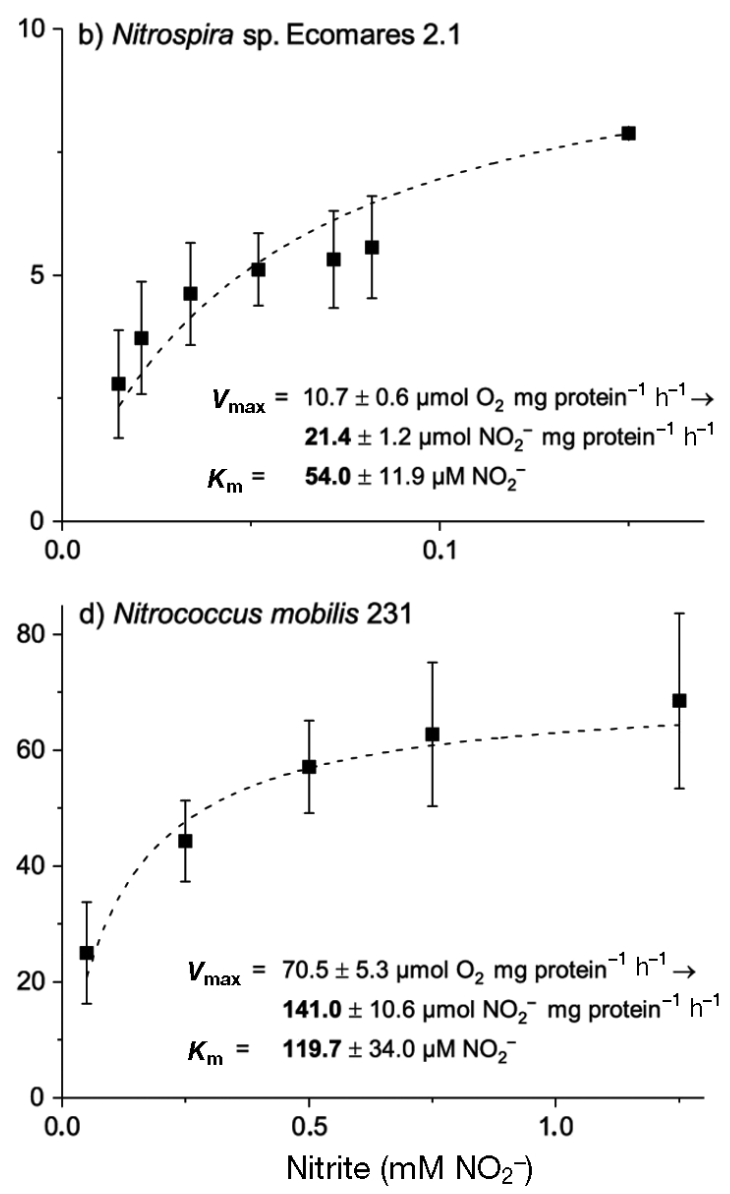

Fig. 1. Nitrite oxidation kinetics of Nitrospina watsonii 347, Nitrospira sp. Ecomares 2.1, Nitrobacter sp. 311, and Nitrococcus mobilis 231. Michaelis-Menten plots of oxygen uptake versus nitrite concentration of early-stationary-phase cells at $28^{\circ} \mathrm{C}$. Mean values and standard deviations resulted from 2 to 4 biological replicates (cf. Table 2). The kinetic parameters were calculated by non-linear fitting of Michaelis-Menten equation to the data 
Nitrococcus mobilis 231 had the highest maximum oxidation activities $\left(141 \pm 11 \mu \mathrm{mol} \mathrm{NO}{ }^{-} \mathrm{mg}_{\text {protein }}{ }^{-1}\right.$ $\mathrm{h}^{-1}$ ), followed by Nitrobacter sp. 311 (95 $\pm 7 \mu \mathrm{mol}$ $\mathrm{NO}_{2}^{-}$mg protein ${ }^{-1} \mathrm{~h}^{-1}$ ). In contrast, the maximum specific activities in Nitrospina watsonii 347 and Nitrospira sp. Ecomares 2.1 were much lower: $37 \pm 2$ and $21 \pm 1 \mathrm{\mu mol} \mathrm{NO}_{2}^{-} \mathrm{mg}$ protein ${ }^{-1} \mathrm{~h}^{-1}$, respectively. Nitrospina watsonii 347, Nitrobacter sp. 311, and Nitrospira sp. Ecomares 2.1 had relatively low $K_{\mathrm{m}}$ values $\left(19 \pm 2,28 \pm 7\right.$, and $54 \pm 12 \mu \mathrm{M} \mathrm{NO}_{2}{ }^{-}$, respectively), whereas Nitrococcus mobilis 231 had a comparatively high value $\left(120 \pm 34 \mu \mathrm{M} \mathrm{NO}_{2}^{-}\right.$; Fig. 1, Table 2).

\section{Isotope analyses and isotope effects}

The initial nitrite concentrations are summarized in Table 1 ; initial nitrite $\delta^{15} \mathrm{~N}$ was $-27.5 \%$. During common lag phases, substrate consumption and isotope changes in each assay were small, and thereafter, concentrations and isotope values of nitrite changed rapidly. Nitrite was stoichiometrically converted to nitrate (not shown in plots). The isotope values of nitrite decreased during nitrite oxidation in all experiments. At the end of the experiment, $\delta^{15} \mathrm{~N}-\mathrm{NO}_{2}{ }^{-}$values of up to $-50 \%$ for Nitrospina watsonii 347 and $-65 \%$ for Nitrospira sp. Ecomares 2.1 were reached. Isotope effects were calculated based on Eq. (4). In Nitrospina watsonii 347 cultures, isotope effects were 8.2 to $10.5 \%$. The replicate regression lines had standard deviations of $<2.3 \%$ and were not significantly different from each other (2-tailed $t$-test, $\mathrm{p}>0.05$ ). We thus calculated a mean isotope effect, $\varepsilon$, of $9.7 \pm$ $0.8 \%$ (Fig. 2a, Table 1). In Nitrospira sp. Ecomares 2.1 cultures, $\varepsilon$ ranged from 9.0 to $11.5 \%$. The standard deviation of each regression was smaller than $0.3 \%$, and replicates were statistically similar (2tailed $t$-test, $\mathrm{p}>0.05)$. Therefore, we calculated a mean isotope effect of $10.2 \pm 0.9 \%$ (Fig. $2 b$, Table 1 ).

Table 2. Results of nitrite oxidation experiments: mean $( \pm \mathrm{SD})$ maximum specific activities $\left(V_{\max }\right)$ and half-saturation constants $\left(K_{\mathrm{m}}\right)$ of 4 marine nitrite oxidizing bacteria (NOB). Number of biological replicates in parentheses

\begin{tabular}{|lcc|}
\hline Bacteria species & $\begin{array}{c}V_{\max } \pm \mathrm{SD} \\
\left(\mu \mathrm{mol} \mathrm{NO}_{2}{ }^{-} \mathrm{mg}\right. \\
\left.\operatorname{protein}^{-1} \mathrm{~h}^{-1}\right)\end{array}$ & $\begin{array}{c}K_{\mathrm{m}} \pm \mathrm{SD} \\
\left(\mu \mathrm{NO}_{2}{ }^{-}\right)\end{array}$ \\
\hline Nitrospina watsonii 347 (2) & $36.8 \pm 2.2$ & $18.7 \pm 2.1$ \\
Nitrospira sp. Ecomares 2.1 (4) & $21.4 \pm 1.2$ & $54.0 \pm 11.9$ \\
Nitrobacter sp. 311 (3) & $95.2 \pm 7.0$ & $27.6 \pm 6.7$ \\
Nitrococcus mobilis 231 (3) & $141.0 \pm 10.6$ & $119.7 \pm 34.0$ \\
\hline
\end{tabular}

Overall, we found that the $\varepsilon$ of Nitrospira sp. Ecomares 2.1 was not significantly different from that determined in Nitrospina watsonii 347 ( $p$ > 0.05).

\section{DISCUSSION}

\section{Nitrite oxidation kinetics}

So far, investigations on nitrite oxidation kinetics have mainly been based on non-marine pure cultures, enrichment cultures, or natural assembles (Prosser 1989, Both et al. 1992, Laanbroek et al. 1994, Schramm et al. 1999, Blackburne et al. 2007, Nowka et al. 2015). The aim of this study was to investigate the substrate affinity of marine NOB to link it to environmental conditions and nitrite oxidation kinetics, which thus far has been difficult because nitrite affinity of marine NOB had not yet been investigated in pure cultures. To close this gap, we investigated the nitrite oxidation kinetics of 4 marine NOB genera, including NOB with NXR oriented towards the cytoplasm and periplasm, respectively, and compared them with non-marine NOB strains (Fig. 3). The investigated marine $K_{\mathrm{m}}$ values varied from 19 to $120 \mu \mathrm{M} \mathrm{NO}_{2}^{-}$(Fig. 1, Table 2), which is rather narrow and at the low end of $K_{\mathrm{m}}$ values reported so far in comparison to all reported kinetics today that span over 2 orders of magnitude between 9 and $>1000 \mu \mathrm{M}$ $\mathrm{NO}_{2}{ }^{-}$(Fig. 3) (Nowka et al. 2015 and references therein). In nature, NOB compete for nitrite, and this competition should be reflected in inter- and intraspecific niche differentiation concerning nitrite oxidation kinetics (Schramm et al. 1999, Kim \& Kim 2006, Nogueira \& Melo 2006, Blackburne et al. 2007). In the light of relatively similar $K_{\mathrm{m}}$ values, these niche differentiations seem to be less pronounced among marine NOB, probably because the availability of nitrite as a substrate is normally low (Wada \& Hatton 1971). $K_{\mathrm{m}}$ values of all the marine NOB we investigated seem to represent an adaptation to these low nitrite concentrations.

Using whole cells from isolates to calculate oxidation kinetics is a well-established method, and thus our calculated $K_{\mathrm{m}}$ values are comparable to previous studies with data from pure cultures (Both et al. 1992, Laanbroek et al. 1994). Furthermore, the results are an important guideline for environmental studies. Even though substrate affinities in the presented dataset are $>20 \mu \mathrm{M} \mathrm{NO}_{2}{ }^{-}$, our kinetic experiments revealed ongoing nitrite oxidation at low substrate concentrations (i.e. $16 \mu \mathrm{M}$ for Nitrospina watsonii 347, $15 \mu \mathrm{M}$ for Nitrospira sp. Ecomares 2.1, $10 \mu \mathrm{M}$ for 


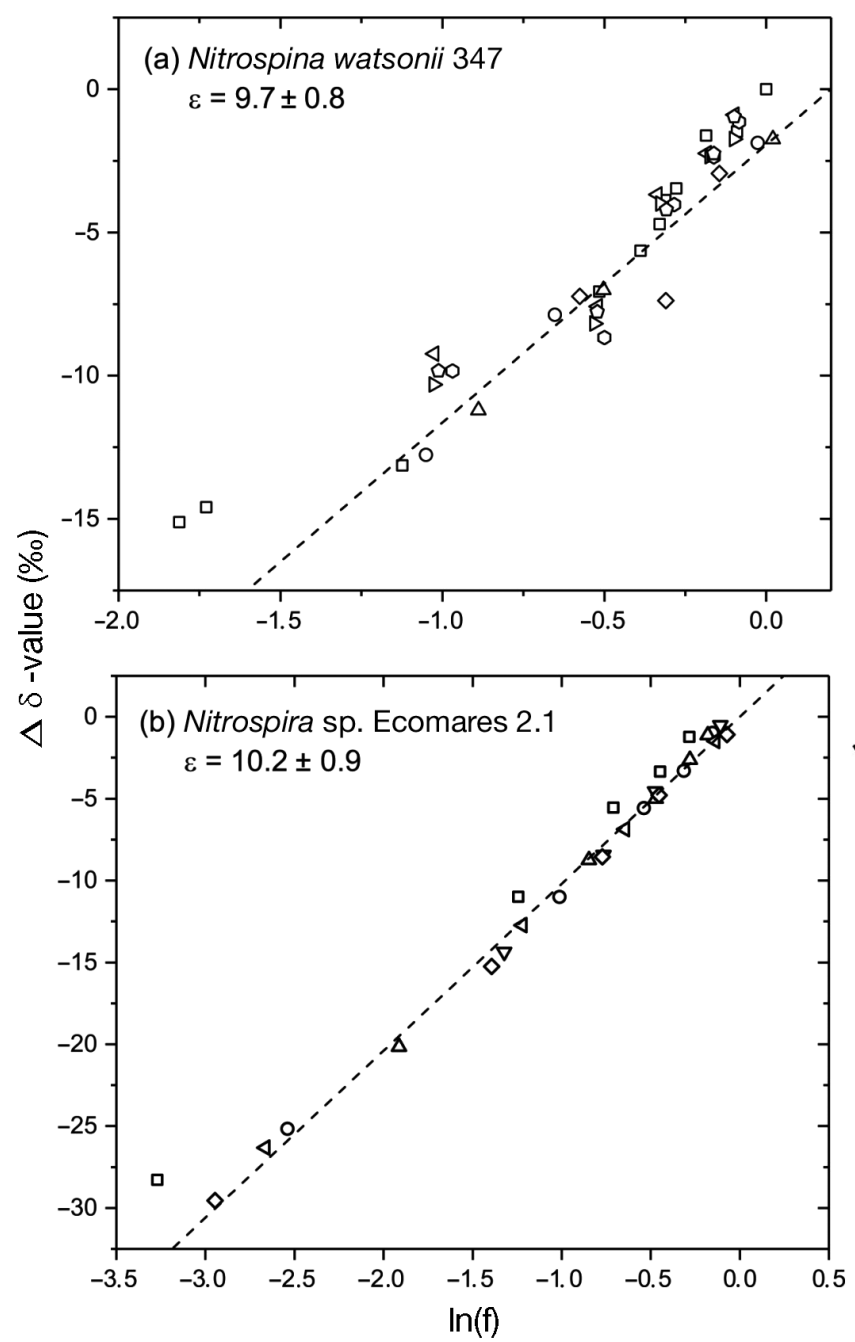

Fig. 2. Rayleigh-plot for (a) 7 Nitrospina watsonii 347 experiments and (b) 6 Nitrospira sp. Ecomares 2.1 experiments. Decrease of $\delta^{15} \mathrm{~N}-\mathrm{NO}_{2}{ }^{-}$relative to the initial $\delta^{15} \mathrm{~N}_{-} \mathrm{NO}_{2}{ }^{-}$is plotted as a function of $\ln \left(\mathrm{NO}_{2}^{-} / \mathrm{NO}_{2}^{-}\right.$initial $)$during nitrite oxidation (cf. Granger et al. 2004 and our Eq. 4). Every experiment has its own symbols. Standard deviation of a sample is $<0.3 \%$ and smaller than the symbol. The average of all regressions defines the dashed line and the corresponding isotope effect $(\varepsilon)$ with an average $\varepsilon$ of $9.7 \pm 0.8 \%$ in the case of Nitrospina watsonii 347 (a), and an average $\varepsilon$ of $10.2 \pm$ $0.9 \%$ in the case of Nitrospira sp. Ecomares 2.1 (b)

Nitrobacter sp. 311, and $50 \mu \mathrm{M}$ for Nitrococcus mobilis 231) (Fig. 1). We assume, though, that environmental conditions are probably more complex due to coupled processes and different bacterial assemblages. Nevertheless, the results obtained should be seen as one vital component for the determination of NOB kinetics.

The $K_{\mathrm{m}}$ value of Nitrospira sp. Ecomares 2.1 (54 $\mu \mathrm{M}$ $\mathrm{NO}_{2}{ }^{-}$) is high compared to other Nitrospira species. The lowest $K_{\mathrm{m}}$ values in this genus were measured in

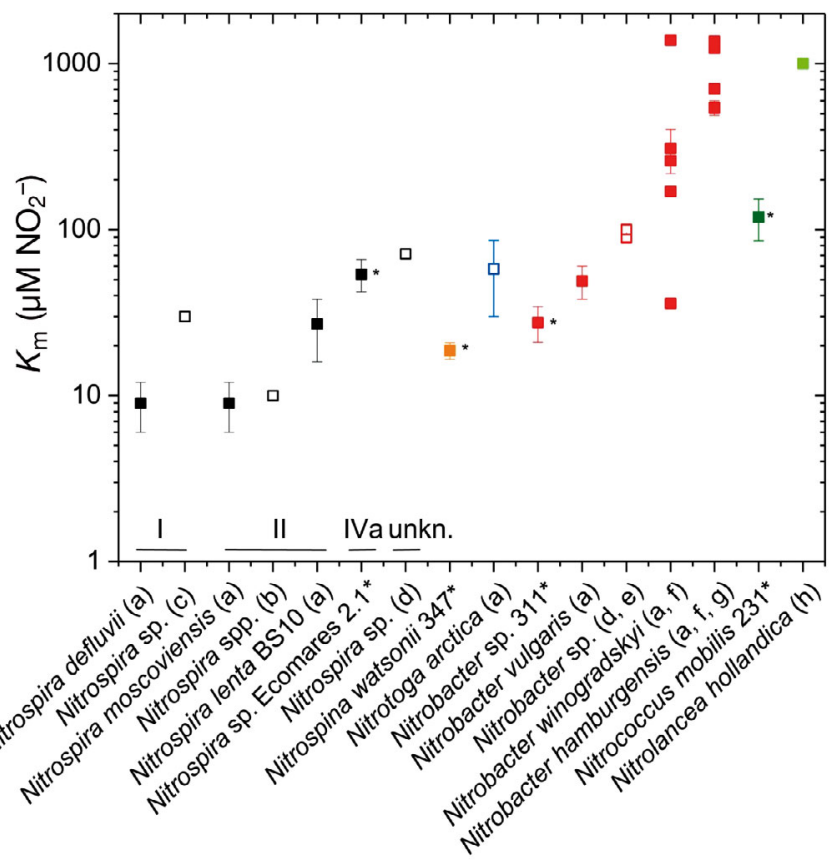

Fig. 3. Nitrite affinities of Nitrospira (black), Nitrospina (orange), Nitrotoga (blue), Nitrobacter (red), Nitrococcus (dark green), and Nitrolancea (light green). Nitrospira lineages are indicated as I, II, IVa or unknown above the species name (modified after Nowka et al. 2015). Marine strains from this study are indicated with an asterisk $\left({ }^{*}\right)$. Filled symbols: pure cultures; open symbols: enrichment cultures. Further half-saturation constant $\left(K_{\mathrm{m}}\right)$ values are from references (a) Nowka et al. (2015), (b) Schramm et al. (1999), (c) Maixner et al. (2006), (d) Blackburne et al. (2007), (e) Vadivelu et al. (2006), (f) Both et al. (1992), (g) Laanbroek et al. (1994), and (h) Sorokin et al. (2012)

Nitrospira moscoviensis (isolate from heating systems; $9 \mu \mathrm{M} \mathrm{NO}_{2}^{-}$) and Nitrospira defluvii (activated sludge; $9 \mu \mathrm{M} \mathrm{NO}_{2}^{-}$; Nowka et al. 2015, our Figs. 1 \& $3)$. One possible explanation for the relatively high $K_{\mathrm{m}}$ values of Nitrospira sp. Ecomares 2.1 may be its origin; this strain was isolated from a moving-bed reactor of a fish farm, where high nitrite concentrations are common (Keuter et al. 2011).

All the other species we investigated were isolated from natural marine environments. Nitrospina watsonii 347 isolated from the Black Sea had the lowest $K_{\mathrm{m}}$ value of $19 \mu \mathrm{M} \mathrm{NO}_{2}^{-}$. Interestingly, Nitrobacter sp. 311 had the second smallest $K_{\mathrm{m}}$ value of our investigated marine species, and of all Nitrobacter species investigated to date (Fig. 3). Isolates from soils, like Nitrobacter hamburgensis and Nitrobacter winogradskyi, have significantly higher $K_{\mathrm{m}}$ values of up to $1370 \mu \mathrm{M}$ (Both et al. 1992, Laanbroek et al. 1994). Within the marine NOB, Nitrococcus mobilis 231 has the highest $K_{\mathrm{m}}$ value of $120 \mathrm{\mu M} \mathrm{NO}_{2}{ }^{-}$, which is in the range reported for Nitrobacter. High $K_{\mathrm{m}}$ values of $\mathrm{Ni}$ - 
trobacter and Nitrococcus indicate low substrate affinity, which could be due to low affinities of the nitrite transporter proteins that shuttle nitrite across the cytoplasmic membrane (Nowka et al. 2015).

Overall, our results are somewhat ambiguous. We expected $K_{\mathrm{m}}$ values to fall in the lower range, indicating high substrate affinities, because marine nitrite concentrations are usually low. This is, however, not entirely the case - while $K_{\mathrm{m}}$ values indeed generally are at the lower end of those reported so far, other non-marine NOB species within the genus of Nitrospira exhibit even higher substrate affinities and lower $K_{\mathrm{m}}$ values (Nowka et al. 2015). We speculate that the relatively narrow range of marine kinetics represents an adaption to constant low substrate concentrations in the ocean in comparison to much more diverse conditions in terrestrial habitats.

\section{Inverse kinetic isotope effects during nitrite oxidation}

In accordance with previous studies (Casciotti 2009, Buchwald \& Casciotti 2010, our Fig. 4) we found that the isotope effect of nitrite oxidation is inverse, so that the nitrite pool is successively depleted in ${ }^{15} \mathrm{~N}$. This inverse effect is because in a transition state complex with NXR and water molecules, ${ }^{15} \mathrm{NO}_{2}{ }^{-}$is preferentially oxidized to nitrate, whereas the complex with ${ }^{14} \mathrm{NO}_{2}{ }^{-}$is more likely to decompose before further oxidation (Friedman et al. 1986).

In our experiments, we found isotope effects of $9.7 \pm 0.8 \%$ for Nitrospina watsonii 347 (Fig. 2a) and $10.2 \pm 0.8 \%$ for Nitrospira sp. Ecomares 2.1 (Fig. 2b, Table 1). This is in line with the previously determined isotope effect of nitrite oxidation by Nitrospira marina (9.1 $\pm 1.8 \%$; Buchwald \& Casciotti 2010), but clearly lower than the considerably varying isotope effects of the marine species Nitrococcus mobilis (12.8 \pm 1.5\%; Casciotti 2009 to $20.2 \pm 2.8 \%$; Buchwald \& Casciotti 2010) or Nitrobacter sp. 355 (20.6 \pm $3.2 \%$; Buchwald \& Casciotti 2010). We point out that we investigated Nitrobacter sp. 311 regarding nitrite oxidation kinetics, whereas Buchwald \& Casciotti (2010) investigated the isotope effect of Nitrobacter sp. 355 in their study.

Interestingly, it seems that the differences in isotope effects can be linked to variability in $K_{\mathrm{m}}$ values. Nitrobacter and Nitrococcus exhibit more inverse isotope effects and generally have high $K_{\mathrm{m}}$ values and thus low substrate affinities, whereas Nitrospina and Nitrospira, with slightly less inverse isotope effects, have high substrate affinities. We speculate

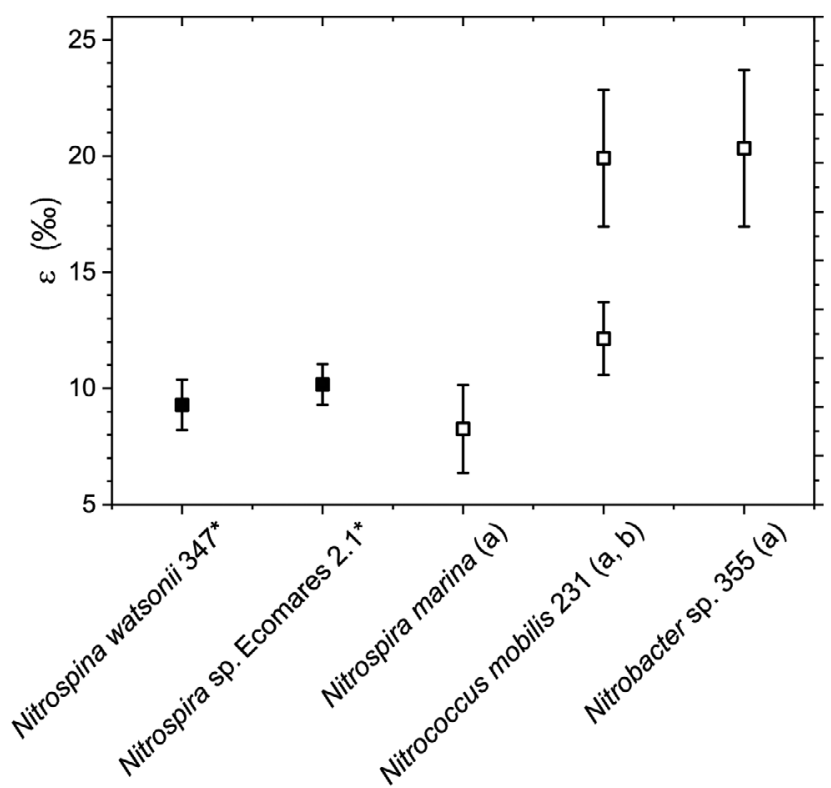

Fig. 4. Overview of isotope effects ( $\varepsilon$ ) during nitrite oxidation of this study $\left({ }^{*}\right)$ and others: references (a) Buchwald \& Casciotti (2010) and (b) Casciotti (2009)

that these high affinities might be reflected in a more efficient turnover of nitrite bearing the light ${ }^{14} \mathrm{~N}$ species, possibly due to a better stabilization of the transition state. This would then result in a lower bulk isotope effect. The contrary might thus apply for Nitrobacter and Nitrococcus with significantly lower substrate affinities: If the transition state decomposed more often and the higher stability with ${ }^{15} \mathrm{~N}$ was more pronounced, these would promote a more pronounced isotope effect.

Beside substrate affinity, the orientation of NXR enzymes and thus energy efficiency differ. Nitrospina and Nitrospira with NXRs oriented towards the periplasm are more competitive at lower nitrite concentrations than Nitrobacter and Nitrococcus with cytoplasmically oriented NXRs (Sorokin et al. 2012). The higher efficiency of periplasmic NXR conserves more energy per oxidized nitrite molecule. The surrounding water provides the additional oxygen atom for the oxidation of nitrite, and 2 protons are released in the periplasmic space of NOB with periplasmic NXR. Additionally, during $\mathrm{O}_{2}$ reduction to water, 2 protons are consumed in the cytoplasm. Therefore, the activity of periplasmic NXR directly contributes to the proton motive force. However, in NOB with cytoplasmic NXR, protons are released and consumed on the same side of the membrane, and thus no contribution to the proton motive force occurs and little energy is obtained during nitrite oxidation (Lücker et al. 2010). The orientation of NXR therefore distin- 
guishes between a more economical pathway (NXR towards periplasm, e.g. Nitrospina and Nitrospira), and a less energy efficient pathway (NXR towards cytoplasm, e.g. Nitrobacter and Nitrococcus).

Another reason for the range in isotope effects may be the orientation of NXR with regards to nitrite transport, as suggested previously by Buchwald \& Casciotti (2010). In cytoplasmically oriented NXR (Nitrobacter and Nitrococcus), transporters shuttle nitrite into and nitrate out of the cell (Spieck et al. 1996, Starkenburg et al. 2006, Sorokin et al. 2012) to avoid accumulation of nitrate in the cell and potential unfavourable conditions. This transport can potentially be a bottleneck for oxidation, depending on the substrate affinity and activity of the transporter (Daims et al. 2016). In periplasmically oriented NXR (Nitrospira and Nitrospina) neither nitrite nor nitrate need to be transported through the cytoplasmic membrane, which hinders active enrichment and may be reflected in lower nitrite availability, so that a more efficient turnover of nitrite is an advantage.

Moreover, the 2 groups of NXRs are not only separated by their subcellular orientation, but also by their evolutionary development based on their phylogenetic affiliation within the type II DMSO reductase family of molybdopterin cofactor-binding enzymes and subcellular location (e.g. Lücker et al. 2013). Nitrospira and Nitrospina lack intracytoplasmic membranes and NXRs oxidize nitrite on the periplasmic side of the membrane (Lücker et al. 2013). NXRs of these NOB belong to a distinct phylogenetic lineage within the type II enzymes of the DMSO reductase family (Lücker et al. 2010, Lücker et al. 2013), which cluster together with NxrAs of anammox bacteria. This NXR type clusters together with the anammox organism 'Candidatus K. stuttgartiensis' (Lücker et al. 2010).

In contrast, Nitrobacter, Nitrococcus, and Nitrolancea oxidize nitrite on the cytoplasmic side of the membrane, and this type of NXR is closer related to the respiratory nitrate reductase (NAR) of denitrifying bacteria (Lücker et al. 2010, Sorokin et al. 2012). Thus, the differences in isotope effects may reflect the NxrA phylogeny. However, anammox-bacteria oxidize nitrite in the anammoxosome (de Almeida et al. 2015) with an inverse isotope effect of about $31 \%$ (Brunner et al. 2013), which is much more pronounced than what we found in Nitrospina and Nitrospira. Indeed, the previously determined isotope effects of Nitrobacter and Nitrococcus are apparently more pronounced and thus closer to that of anammox bacteria. This is possibly linked to a high reversibility of nitrite oxidation in anammox bacteria
(Brunner et al. 2013), which may presumably also play a role in Nitrobacter (Sundermeyer-Klinger et al. 1984, Freitag et al. 1987) and in Nitrococcus (Füssel et al. 2017).

\section{Environmental relevance and model application}

Our measurements represent the first assessment of kinetics of 4 marine NOB, and we hypothesize that marine NOB tend to be $K$-strategists, probably because of the low substrate availability and relatively little environmental fluctuations in marine habitats. The marine NOB strains we used in our study belong to environmentally relevant genera. Nitrospina and Nitrococcus in particular are widespread in OMZs, where 30 to $50 \%$ of the global oceanic nitrogen loss takes place (Gruber \& Sarmiento 1997, Codispoti et al. 2001, Gruber \& Galloway 2008). In the Arabian Sea OMZ, Nitrospina spp., and a novel lineage of NxrA clustering between anammox and Nitrospina sequences were identified (Lüke et al. 2016). Nitrospina was further found near Costa Rica in the eastern tropical North Pacific (Buchwald et al. 2015), and Nitrospina and Nitrococcus make up $~ 9 \%$ of the microbial community in the Namibian OMZ (Füssel et al. 2012). There are numerous studies addressing the ubiquitous occurrence of the genus Nitrospina, which make our results to some extent representative for the marine NOB community in at least some sampling sites.

Furthermore, the isotope effects for Nitrospina watsonii 347 and Nitrospira sp. Ecomares 2.1 that we calculated are significantly different from the previously determined higher isotope effects of Nitrococcus and Nitrobacter. These differences have important consequences for the interpretation of nitrification and model calculations. Biogeochemical models are often applied in marine systems where nitrite accumulates, such as the SNM of OMZs (Lam et al. 2011, Gaye et al. 2013), and the isotope effects of nitrite generation and removal are important constraints for such models.

Generally, a wide range of isotope effects has been applied in different models: In the OMZ of the eastern tropical North Pacific off Costa Rica, an isotope effect of $30 \%$ was calculated for nitrite oxidation (Buchwald et al. 2015). In another model study focusing on the eastern tropical South Pacific, measurements of $\delta^{15}{\mathrm{~N}-\mathrm{NO}_{2}}^{-}$could not be reproduced using currently published isotope effects - an isotope effect of $32 \%$ (close to that determined experimentally for anammox bacteria; Brunner et al. 2013) would have been required to reproduce the data (Casciotti 
et al. 2013). Contrastingly, in a recent study on isotopic overprinting during combined nitrificationdenitrification (Granger \& Wankel 2016), the authors used $16.0 \pm 4.5 \%$ as a model parameter for nitrite oxidation, and also on the lower end of the applied isotope effects, Gaye at al. (2013) assumed an isotope effect of $13 \%$ for nitrite oxidation in the Arabian Sea (cf. Casciotti 2009). A change in the isotope effect of nitrite oxidation, even by only $3 \%$, will alter the computed isotope values of nitrite in ocean models ( $\mathrm{T}$. Rixen pers. comm.). The use of such a lower isotope effect may be appropriate because other OMZ regions (like the eastern tropical North Pacific off Costa Rica OMZ, the Namibian OMZ, the Black Sea OMZ, and the Baltic Sea; Labrenz et al. 2007, Fuchsman et al. 2011, Füssel et al. 2012, Spieck et al. 2014, Buchwald et al. 2015) host predominantly Nitrospina, for which we find a low isotope effect in this study. This shows that a more accurate assessment of isotope effects and the kinetic parameters that determine these effects is urgently needed to better constrain biogeochemical models.

\section{CONCLUSIONS}

We investigated the nitrite oxidation kinetics of 4 marine NOB (Nitrospina watsonii 347, Nitrospira sp. Ecomares 2.1, Nitrobacter sp. 311, and Nitrococcus mobilis 231). The range of the $K_{\mathrm{m}}$ values was comparatively narrow, which might reflect a niche specialization towards low substrate concentration and little fluctuation of environmental conditions in marine habitats and places all $K_{\mathrm{m}}$ values of marine NOB in a range similar to clear (terrestrial) $K$-strategists. For Nitrospina watsonii 347 and Nitrospira sp. Ecomares 2.1, we also determined the isotope effects of nitrite oxidation, which were $9.7 \pm 0.8$ and $10.2 \pm 0.9 \%$, respectively. This is in line with former investigations of Nitrospira marina, but significantly different from Nitrobacter sp. 355 and Nitrococcus mobilis 231, which both have significantly higher isotope effects.

Based on our data, we speculate that the significant differences between Nitrospina watsonii 347, Nitrospira sp. Ecomares 2.1, and Nitrospira marina on the one side, and Nitrobacter sp. 355 and Nitrococcus mobilis 231 on the other side, may be due to differences in NXR orientation or phylogenetic relationships because, e.g., anammox bacteria also show a distinctly different (and much more pronounced) isotope effect during nitrite oxidation. Thus, our data sets the basis for an assessment of variances in isotope effects due to phylogeny and enzyme orienta- tion, which should be pursued in the future with an assessment including non-marine NOB.

Furthermore, our investigation of nitrite oxidation kinetic data and isotope effects will help verify and improve biogeochemical models. Models are often applied in hotspots of nitrogen cycling like OMZs, where especially Nitrospina and Nitrococcus are widespread. It may be an interesting perspective to link the dominant nitrite oxidizer species to environmentally determined isotope effects and their relatedness to anammox bacteria. Overall, our data provide an overview of potential nitrite oxidation kinetics and enlarge the database for isotope effects. There is a certain mismatch between measured isotope effects and those assumed in models; some modelling approaches require isotope effects significantly above those measured to date, including in this study. This suggests that a re-evaluation of modelling approaches may be required to match the isotope effects because there is no indication for higher isotope effects in NOB from marine OMZs.

Acknowledgements. This study was partly funded by the Helmholtz Association (VH-NG-721). B.N. was funded by the Deutsche Forschungsgemeinschaft (DFG, German Research Foundation) - Project SP 667/10-1. Three anonymous reviewers are gratefully thanked for suggestions that significantly improved the manuscript.

\section{LITERATURE CITED}

Alawi M, Lipski A, Sanders T, Spieck E (2007) Cultivation of a novel cold-adapted nitrite oxidizing betaproteobacterium from the Siberian Arctic. ISME J 1:256-264

Andrews JH, Harris RF (1986) $r$-and $K$-selection and microbial ecology. In: Marshall KC (ed) Advances in microbial ecology, Vol 9. Plenum Press, New York, NY, p 99-148

* Blackburne R, Vadivelu VM, Yuan Z, Keller J (2007) Kinetic characterisation of an enriched Nitrospira culture with comparison to Nitrobacter. Water Res 41:3033-3042

Böhlke JK, Smith RL, Hannon JE (2007) Isotopic analysis of $\mathrm{N}$ and $\mathrm{O}$ in nitrite and nitrate by sequential selective bacterial reduction to $\mathrm{N}_{2} \mathrm{O}$. Anal Chem 79:5888-5895

Both GJ, Gerards S, Laanbroek HJ (1992) Kinetics of nitrite oxidation in two Nitrobacter species grown in nitritelimited chemostats. Arch Microbiol 157:436-441

* Bristow LA, Dalsgaard T, Tiano L, Mills DB and others (2016) Ammonium and nitrite oxidation at nanomolar oxygen concentrations in oxygen minimum zone waters. Proc Natl Acad Sci USA 113:10601-10606

* Brunner B, Contreras S, Lehmann MF, Matantseva O and others (2013) Nitrogen isotope effects induced by anammox bacteria. Proc Natl Acad Sci USA 110:18994-18999

* Buchwald C, Casciotti KL (2010) Oxygen isotopic fractionation and exchange during bacterial nitrite oxidation. Limnol Oceanogr 55:1064-1074

* Buchwald C, Santoro AE, Stanley RH, Casciotti KL (2015) Nitrogen cycling in the secondary nitrite maximum of the eastern tropical North Pacific off Costa Rica. Global Biogeochem Cycles 29:2061-2081 
Casciotti KL (2009) Inverse kinetic isotope fractionation during bacterial nitrite oxidation. Geochim Cosmochim Acta 73:2061-2076

Casciotti KL, Sigman DM, Hastings MG, Böhlke JK, Hilkert A (2002) Measurement of the oxygen isotopic composition of nitrate in seawater and freshwater using the denitrifier method. Anal Chem 74:4905-4912

Casciotti KL, Sigman DM, Ward BB (2003) Linking diversity and stable isotope fractionation in ammonia-oxidizing bacteria. Geomicrobiol J 20:335-353

Casciotti KL, Buchwald C, McIlvin M (2013) Implications of nitrate and nitrite isotopic measurements for the mechanisms of nitrogen cycling in the Peru oxygen deficient zone. Deep Sea Res I 80:78-93

* Codispoti L, Brandes JA, Christensen J, Devol A, Naqvi S, Paerl HW, Yoshinari T (2001) The oceanic fixed nitrogen and nitrous oxide budgets: Moving targets as we enter the anthropocene? Sci Mar 65:85-105

Daims H, Lücker S, Wagner M (2016) A new perspective on microbes formerly known as nitrite-oxidizing bacteria. Trends Microbiol 24:699-712

de Almeida NM, Neumann S, Mesman RJ, Ferousi C and others (2015) Immunogold localization of key metabolic enzymes in the anammoxosome and on the tubule-like structures of Kuenenia stuttgartiensis. J Bacteriol 197: 2432-2441

* De Boer W, Gunnewiek PK, Veenhuis M, Bock E, Laanbroek $\mathrm{H}$ (1991) Nitrification at low pH by aggregated chemolithotrophic bacteria. Appl Environ Microbiol 57:36003604

* Dore JE, Karl DM (1996) Nitrification in the euphotic zone as a source for nitrite, nitrate, and nitrous oxide at Station ALOHA. Limnol Oceanogr 41:1619-1628

Ehrich S, Behrens D, Lebedeva E, Ludwig W, Bock E (1995) A new obligately chemolithoautotrophic, nitrite-oxidizing bacterium, Nitrospira moscoviensis sp. nov. and its phylogenetic relationship. Arch Microbiol 164:16-23

Fiencke C, Spieck E, Bock E (2005) Nitrifying bacteria. In: Werner D, Newton WE (eds) Nitrogen fixation in agriculture, forestry, ecology, and the environment. Springer, Dordrecht, p 255-276

Freitag A, Rudert M, Bock E (1987) Growth of Nitrobacter by dissimilatoric nitrate reduction. FEMS Microbiol Lett 48: 105-109

Friedman SH, Massefski W, Hollocher T (1986) Catalysis of intermolecular oxygen atom transfer by nitrite dehydrogenase of Nitrobacter agilis. J Biol Chem 261:10538-10543

Fuchsman CA, Kirkpatrick JB, Brazelton WJ, Murray JW, Staley JT (2011) Metabolic strategies of free-living and aggregate-associated bacterial communities inferred from biologic and chemical profiles in the Black Sea suboxic zone. FEMS Microbiol Ecol 78:586-603

Füssel J, Lam P, Lavik G, Jensen MM, Holtappels M, Gunter M, Kuypers MM (2012) Nitrite oxidation in the Namibian oxygen minimum zone. ISME J 6:1200-1209

Füssel J, Lücker S, Yilmaz P, Nowka B and others (2017) Adaptability as the key to success for the ubiquitous marine nitrite oxidizer Nitrococcus. Sci Adv 3(11):e1700807

Gaye B, Nagel B, Dähnke K, Rixen T, Emeis KC (2013) Evidence of parallel denitrification and nitrite oxidation in the ODZ of the Arabian Sea from paired stable isotopes of nitrate and nitrite. Global Biogeochem Cycles 27: 1059-1071

Granger J, Wankel SD (2016) Isotopic overprinting of nitrification on denitrification as a ubiquitous and unifying feature of environmental nitrogen cycling. Proc Natl Acad Sci USA 113:E6391-E6400
Granger J, Sigman DM, Needoba JA, Harrison PJ (2004) Coupled nitrogen and oxygen isotope fractionation of nitrate during assimilation by cultures of marine phytoplankton. Limnol Oceanogr 49(5):1763-1773

Grasshoff K, Kremling K, Ehrhardt M (2009) Methods of seawater analysis, 3rd edn. Wiley-VCH, Weinheim

*Gruber N, Galloway JN (2008) An Earth-system perspective of the global nitrogen cycle. Nature 451:293-296

* Gruber N, Sarmiento JL (1997) Global patterns of marine nitrogen fixation and denitrification. Global Biogeochem Cycles 11:235-266

Jacob J, Sanders T, Dähnke K (2016) Nitrite consumption and associated isotope changes during a river flood event. Biogeosciences 13:5649-5659

Kalvelage T, Lavik G, Lam P, Contreras S and others (2013) Nitrogen cycling driven by organic matter export in the South Pacific oxygen minimum zone. Nat Geosci 6: 228-234

Keuter S (2011) Characterization of nitrifying bacteria in marine recirculation aquaculture systems with regard to process optimization. PhD dissertation, University of Hamburg

Keuter S, Kruse M, Lipski A, Spieck E (2011) Relevance of Nitrospira for nitrite oxidation in a marine recirculation aquaculture system and physiological features of a Nitrospira marina-like isolate. Environ Microbiol 13: 2536-2547

Keuter S, Beth S, Quantz G, Schulz C, Spieck E (2017) Longterm monitoring of nitrification and nitrifying communities during biofilter activation of two marine recirculation aquaculture systems (RAS). Int J Aquac Fish Sci 3:051-061

Kim DJ, Kim SH (2006) Effect of nitrite concentration on the distribution and competition of nitrite-oxidizing bacteria in nitratation reactor systems and their kinetic characteristics. Water Res 40:887-894

Kraft B, Tegetmeyer HE, Sharma R, Klotz MG and others (2014) The environmental controls that govern the end product of bacterial nitrate respiration. Science 345 : 676-679

KLaanbroek HJ, Bodelier PL, Gerards S (1994) Oxygen consumption kinetics of Nitrosomonas europaea and Nitrobacter hamburgensis grown in mixed continuous cultures at different oxygen concentrations. Arch Microbiol 161:156-162

Labrenz M, Jost G, Jürgens K (2007) Distribution of abundant prokaryotic organisms in the water column of the central Baltic Sea with an oxic-anoxic interface. Aquat Microb Ecol 46:177-190

K Lam P, Kuypers MM (2011) Microbial nitrogen cycling processes in oxygen minimum zones. Annu Rev Mar Sci 3: 317-345

Lam P, Jensen MM, Kock A, Lettmann KA and others (2011) Origin and fate of the secondary nitrite maximum in the Arabian Sea. Biogeosciences 8:1565-1577

Lomas MW, Lipschultz F (2006) Forming the primary nitrite maximum: Nitrifiers or phytoplankton? Limnol Oceanogr 51:2453-2467

Lücker S, Wagner M, Maixner F, Pelletier E and others (2010) A Nitrospira metagenome illuminates the physiology and evolution of globally important nitriteoxidizing bacteria. Proc Natl Acad Sci USA 107: 13479-13484

K Lücker S, Nowka B, Rattei T, Spieck E, Daims H (2013) The genome of Nitrospina gracilis illuminates the metabolism and evolution of the major marine nitrite oxidizer. Front Microbiol 4:27 
Lüke C, Speth DR, Kox MA, Villanueva L, Jetten MS (2016) Metagenomic analysis of nitrogen and methane cycling in the Arabian Sea oxygen minimum zone. PeerJ 4:e1924

MacArthur R, Wilson E (1967) The theory of biogeography. Princeton University Press, Princeton, NJ

Maixner F, Noguera DR, Anneser B, Stoecker K, Wegl G, Wagner M, Daims H (2006) Nitrite concentration influences the population structure of Nitrospira-like bacteria. Environ Microbiol 8:1487-1495

Mariotti A, Germon JC, Hubert P, Kaiser P, Letolle R, Tardieux A, Tardieux P (1981) Experimental determination of nitrogen kinetic isotope fractionation: some principles; illustration for the denitrification and nitrification processes. Plant Soil 62:413-430

Meincke M, Bock E, Kastrau D, Kroneck PM (1992) Nitrite oxidoreductase from Nitrobacter hamburgensis: redox centers and their catalytic role. Arch Microbiol 158: 127-131

Ngugi DK, Blom J, Stepanauskas R, Stingl U (2016) Diversification and niche adaptations of Nitrospina-like bacteria in the polyextreme interfaces of Red Sea brines. ISME J 10:1383-1399

Nogueira R, Melo LF (2006) Competition between Nitrospira spp. and Nitrobacter spp. in nitrite-oxidizing bioreactors. Biotechnol Bioeng 95:169-175

Nowka B, Daims H, Spieck E (2015) Comparison of oxidation kinetics of nitrite-oxidizing bacteria: nitrite availability as a key factor in niche differentiation. Appl Environ Microbiol 81:745-753

Olson RJ (1981) Differential photoinhibition of marine nitrifying bacteria: a possible mechanism for the formation of the primary nitrite maximum. J Mar Res 39:227-238

Peng X, Fuchsman CA, Jayakumar A, Warner MJ, Devol AH, Ward BB (2016) Revisiting nitrification in the eastern tropical South Pacific: a focus on controls. J Geophys Res Oceans 121:1667-1684

Prosser JI (1989) Autotrophic nitrification in bacteria. Adv Microb Physiol 30:125-181

Santoro A, Sakamoto C, Smith J, Plant J and others (2013) Measurements of nitrite production in and around the primary nitrite maximum in the central California Current. Biogeosciences 10:7395-7410

Schramm A, de Beer D, van den Heuvel JC, Ottengraf S, Amann R (1999) Microscale distribution of populations and activities of Nitrosospira and Nitrospira spp. along a macroscale gradient in a nitrifying bioreactor: quantification by in situ hybridization and the use of microsensors. Appl Environ Microbiol 65:3690-3696

Sigman DM, Casciotti KL, Andreani M, Barford C, Galanter M, Bohlke JK (2001) A bacterial method for the nitrogen isotopic analysis of nitrate in seawater and freshwater. Anal Chem 73:4145-4153

Smith PK, Krohn RI, Hermanson G, Mallia A and others (1985) Measurement of protein using bicinchoninic acid. Anal Biochem 150:76-85

Sorokin DY, Lücker S, Vejmelkova D, Kostrikina NA and others (2012) Nitrification expanded: discovery, physiology and genomics of a nitrite-oxidizing bacterium from the phylum Chloroflexi. ISME J 6:2245-2256

Spieck E, Bock E (2005) The lithoautotrophic nitrite-oxidizing bacteria. In: Garrity G (ed) Bergey's manual of systematic bacteriology, Vol 2: the Proteobacteria. Part A: introductory essays. Springer, New York, NY, p 149-154

Spieck E, Lipski A (2011) Cultivation, growth physiology, and chemotaxonomy of nitrite-oxidizing bacteria. Methods Enzymol 486:109-130

Spieck E, Müller S, Engel A, Mandelkow E, Patel H, Bock E
(1996) Two-dimensional structure of membrane-bound nitrite oxidoreductase from Nitrobacter hamburgensis. J Struct Biol 117:117-123

Spieck E, Ehrich S, Aamand J, Bock E (1998) Isolation and immunocytochemical location of the nitrite-oxidizing system in Nitrospira moscoviensis. Arch Microbiol 169: 225-230

Spieck E, Keuter S, Wenzel T, Bock E, Ludwig W (2014) Characterization of a new marine nitrite oxidizing bacterium, Nitrospina watsonii sp. nov., a member of the newly proposed phylum 'Nitrospinae'. Syst Appl Microbiol 37:170-176

* Starkenburg SR, Chain PS, Sayavedra-Soto LA, Hauser L and others (2006) Genome sequence of the chemolithoautotrophic nitrite-oxidizing bacterium Nitrobacter winogradskyi Nb-255. Appl Environ Microbiol 72: 2050-2063

Starkenburg SR, Larimer FW, Stein LY, Klotz MG and others (2008) Complete genome sequence of Nitrobacter hamburgensis X14 and comparative genomic analysis of species within the genus Nitrobacter. Appl Environ Microbiol 74:2852-2863

Sundermeyer-Klinger H, Meyer W, Warninghoff B, Bock E (1984) Membrane-bound nitrite oxidoreductase of Nitrobacter: evidence for a nitrate reductase system. Arch Microbiol 140:153-158

Teske A, Alm E, Regan J, Toze S, Rittmann B, Stahl D (1994) Evolutionary relationships among ammonia- and nitriteoxidizing bacteria. J Bacteriol 176:6623-6630

*Vadivelu VM, Yuan Z, Fux C, Keller J (2006) Stoichiometric and kinetic characterisation of Nitrobacter in mixed culture by decoupling the growth and energy generation processes. Biotechnol Bioeng 94:1176-1188

* Wada E, Hatton A (1971) Nitrite metabolism in the euphotic layer of the central North Pacific Ocean. Limnol Oceanogr 16:766-772

Ward BB (2011) Nitrification in the ocean. In: Ward BB, Arp DJ, Klotz MG (eds) Nitrification. ASM Press, Washington, DC, p 325-345

Ward BB, Carlucci AF (1985) Marine ammonia-and nitriteoxidizing bacteria: serological diversity determined by immunofluorescence in culture and in the environment. Appl Environ Microbiol 50:194-201

Watson SW, Waterbury JB (1971) Characteristics of two marine nitrite oxidizing bacteria, Nitrospina gracilis nov. gen. nov. sp. and Nitrococcus mobilis nov. gen. nov. sp. Arch Mikrobiol 77:203-230

Watson SW, Bock E, Valois FW, Waterbury JB, Schlosser U (1986) Nitrospira marina gen. nov. sp. nov.: a chemolithotrophic nitrite-oxidizing bacterium. Arch Microbiol 144: $1-7$

Watson S, Bock E, Harms H, Koops H, Hooper A (1989) Nitrifying bacteria. In: Staley JT, Bryant MP, Pfennig N, Holt JG (eds) Bergey's manual of systematic bacteriology, Vol 3. Williams \& Wilkins, Baltimore, MD, p 1808-1834

Winogradsky S (1892) Contributions à la morphologie des organismes de la nitrification. Arch Biol Sci 1:88-137

*Woese CR, Stackebrandt E, Weisburg WG, Paster BJ and others (1984) The phylogeny of purple bacteria: the alpha subdivision. Syst Appl Microbiol 5:315-326

Woese CR, Weisburg WG, Hahn CM, Paster BJ and others (1985) The phylogeny of purple bacteria: the gamma subdivision. Syst Appl Microbiol 6:25-33

*Wright JJ, Konwar KM, Hallam SJ (2012) Microbial ecology of expanding oxygen minimum zones. Nat Rev Microbiol 10:381-394 